\title{
PHARMACOKINETIC BEHAVIOR OF MARBOFLOXACIN IN PLASMA FROM CHICKENS AT DIFFERENT SEASONS
}

\author{
Natalia Francisca Urzúa Pizarroํ, Carlos Alberto Errecalde ${ }^{1}$, Guillermo Fermin Prieto ${ }^{1}$, \\ Carlos Fernando Lüders ${ }^{2}$, María Paula Tonini ${ }^{1}$, Eduardo Jesús Picco ${ }^{3}$ \\ ${ }^{1}$ Department of Animal Clinic, Faculty of Agronomy and Veterinary Medicine, \\ National University of Rio Cuarto, Route $36 \mathrm{Km}$ 601, Rio Cuarto, Argentina \\ ${ }^{2}$ School of Veterinary Medicine, Catholic University of Temuco, \\ Casilla 15D, Temuco, Chile \\ ${ }^{3}$ Department of Pharmacology, Faculty of Veterinary Sciences, \\ National University of the Coast, Kreder 2805, Esperanza, Argentina
}

Received 12 December 2016; Received in revised form 10 March 2017; Accepted 24 March 2017

\begin{abstract}
The purpose of this study was to evaluate the differences in the disposition and plasma pharmacokinetic behavior of marbofloxacin (MAR) in broiler chickens at different seasons. Chicken broilers $(n=345)$ were used, in lots of 5 individuals, divided into 6 groups depending on the way of administration, intravenous or oral (dose $2 \mathrm{mg} / \mathrm{kg}$ ) and the test period. Post-administration plasma samples were obtained at different times, intravenously ( 0.08 to 24 hours) and orally ( 0.25 to 120 hours). A liquid-liquid extraction of MAR was performed by high-performance liquid chromatography (HPLC) with a fluorescent detector. The plasma concentrations obtained at the different sampling times of each season, were analyzed with ANOVA and pharmacokinetic analysis was conducted with the PK Solution 2.0 software. The concentration of marbofloxacin in plasma was significantly lower in winter and summer than in spring, with MAR being detected in winter up to 72 hours post-application, coinciding with the differences in MAR pharmacokinetics parameters with increase in the average residence time (MRT) is 9.4 hours in winter. Increased clearance MAR in summer $(7.5 \mathrm{ml} / \mathrm{min} / \mathrm{kg}$ ) coincides with MRT 6.3 hours. Finally, the oral bioavailability of MAR is lower in summer and winter $(86 \pm 1.7 \%$ and $78 \pm 3.1 \%)$ than in spring $(94 \pm 5.2 \%)$. There are differences in the disposition and plasma pharmacokinetic behavior of MAR applied orally in broiler chickens, coinciding with the physiological changes in the thermoregulation of birds, considering its correct therapeutic management and contributing to provide safe food for human consumption.
\end{abstract}

Key words: pharmacokinetics, marbofloxacin, chickens, seasons changes

\section{INTRODUCTION}

The intensification of the production in poultry farms increases the risk of diseases, expending the use of antimicrobial prophylactic, control or treatment agents $(1,2)$. Fluoroquinolones which are the most used antimicrobial agents in veterinary

Corresponding author: Dr. Natalia Urzúa Pizarro, $\mathrm{PhD}$

E-mail address: nurzuapizarro@ayv.unrc.edu.ar

Present address: Department of Animal Clinic, Faculty of Agronomy and Veterinary Medicine, National University of Rio Cuarto, Route $36 \mathrm{Km} 601$, Rio Cuarto, Argentina

Phone: +54(0358) 4641986 Fax: +54(0358) 4680280

Copyright: () 2017 Pizarro N. This is an open-access article published under the terms of the Creative Commons Attribution License which permits unrestricted use, distribution, and reproduction in any medium, provided the original author and source are credited.

Competing Interests: The authors have declared that no competing interests exist.

Available Online First: 10 June 2017

Published on: 15 October 2017

https://doi.org/10.1515/macvetrev-2017-0019 medicine are used intensively in poultry production $(1,3)$.

Marbofloxacin(MAR) is a fluoroquinolone effective against a wide range of important poultry pathogens, including Mycoplasma gallisepticum, Escherichia coli and Pasteurella multocida. It has a low plasma protein binding, it benefits from a rapid and complete absorption, a broad distribution with good concentrations in tissues and bodily fluids, a moderate elimination and a high bioavailability, which are all ideal pharmacokinetic characteristics to use in poultry (4-8).

There are factors that modify this pharmacokinetic behavior such as race, age, weight, environmental factors, among others. Failure to identify these factors leads to errors in predicting the dose-exposure relation within a population $(9$, 
10). It is important to know the modifications that these factors bring about in the pharmacokinetics of drugs in food producing animals, in order to improve therapeutic management and generate food free of pharmacological residues (11).

Finally, the objective of this study is to evaluate the differences in the disposition and pharmacokinetic behavior of MAR in broiler chickens, administered orally and intravenously, in comfort temperature (spring), summer and winter.

\section{MATERIAL AND METHODS}

\section{Experimental design}

For the study, healthy Ross broiler chickens $(n=345)$ were used. They were 30 days old and each weighed $0.98 \pm 0.02 \mathrm{~kg}$. They were randomly divided into 6 groups, a spring group A $(n=50)$ and group $\mathrm{B}(\mathrm{n}=65)$, a summer group $\mathrm{C}(\mathrm{n}=50)$ and a group $\mathrm{D}$ $(n=65)$, a winter group $\mathrm{E}(\mathrm{n}=50)$ and a group $\mathrm{F}(\mathrm{n}=65)$.

For each time of the year, the chickens were placed in a room that maintained the environmental conditions of the study station: spring group with an ambient temperature of $18.6 \pm 2.5^{\circ} \mathrm{C}$, winter group of $12 \pm 2.9^{\circ} \mathrm{C}$ and summer group of $26.6 \pm 2.3^{\circ} \mathrm{C}$. The temperature was recorded every 8 hours during the study. The birds received food and water ad libitum.

Chickens were given a single dose of $2 \mathrm{mg} / \mathrm{kg}$ of Marbocyl 2\% (Laboratorio Vétoquinol S.A., Spain) applied intravenously or orally, for the latter the dose was administrated after 12 hours fasting. In groups $\mathrm{A}, \mathrm{C}, \mathrm{E}$ the blood was sampled between 0.08 to 24 hours, while in groups B, D and F it was between 0.25 to 120 hours.

\section{Sample processing}

Five chickens were used for each sample extraction time. Blood collection $(5 \mathrm{ml})$ was performed in the axillary vein, and the blood was placed in heparinized tubes and immediately centrifuged for 10 minutes at 2,500 rpm, to obtain the plasma for the study.

To extract the analyte (MAR), a liquid-liquid extraction was used. $200 \mu \mathrm{l}$ of plasma was placed in an eppendorf tube, $800 \mu \mathrm{l}$ of methanol, $200 \mu \mathrm{l}$ of deionized water and $40 \mu \mathrm{l}$ of enrofloxacin $(2.5$ $\mu \mathrm{g} / \mathrm{ml})$ were added as an internal standard. The determination was performed by high performance liquid chromatography (HPLC, Hewlett-Packard 1050 equipment), with a fluorescence detector (Hewlett-Packard 1046-A) and C-18 column (Octadecylsilane $5 \mu \mathrm{m}, 250 \mathrm{~cm}$ x $4.6 \mathrm{~mm}$ ). Analytes were eluted isocratically with a flow rate of $0.8 \mathrm{ml} / \mathrm{min}$, using a mobile phase consisting of deionized water, acetonitrile, and triethylamine (790:200:10 v/v/v) $(12,13)$.

Peak areas in chromatograms of the samples were quantitated using the internal-standard technique, by use of solutions of marbofloxacin and reference standard (enrofloxacin). Standard curves were linear $\left(r^{2}>0.99\right)$ for concentrations ranging from 0.039 to $1.25 \mu \mathrm{g} / \mathrm{ml}$ of plasma for marbofloxacin, and quantification limit was 0.006 $\mu \mathrm{g} / \mathrm{ml}$ and the relative recovery was $86.2 \pm 3.75 \%$ for the ranges $0.0024-2.5 \mu \mathrm{g} / \mathrm{ml}(12)$.

\section{Pharmacokinetic analysis}

The pharmacokinetic study was performed using the Non-compartmental PK Solution 2.0 pharmacokinetic program (14), also using the average MAR concentrations obtained by sampling time, the way of administration, and the average weight of each study group. In addition, marbofloxacin absolute bioavailability $(F)$ for oral administration was calculated by comparing areas under the intravenous plasma curve (AUCiv) with the oral plasma curve (AUCpo) (15).

Statistical analysis was performed with the software InfoStat (16) ANOVA test and Tukey's test to compare plasma concentrations and MAR pharmacokinetic parameters between spring (control), summer and winter.

\section{RESULTS}

Fig. 1 shows the mean plasma concentrations of MAR in broilers in different seasons by intravenous route and Fig. 2 by oral administration.

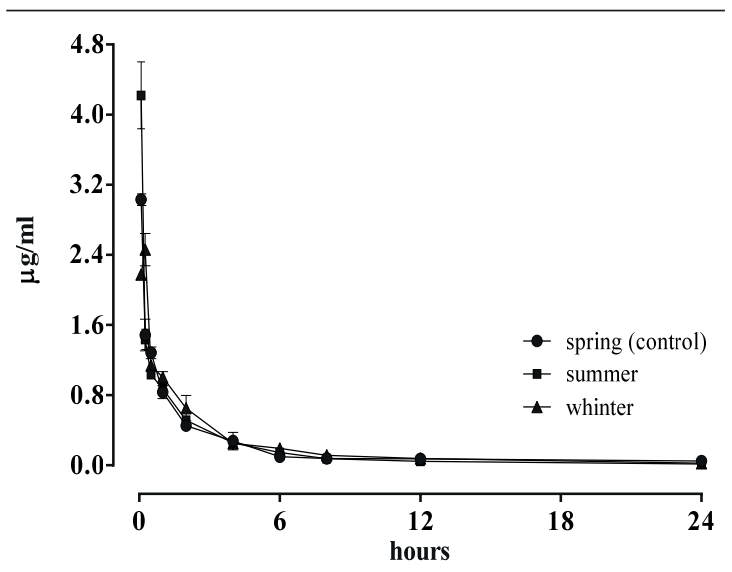

Figure 1. Plasma disposition curve concentrations of $\operatorname{MAR}(\mu \mathrm{g} / \mathrm{ml})$ after intravenous administration in chickens $(2 \mathrm{mg} / \mathrm{kg})$ in different seasons 


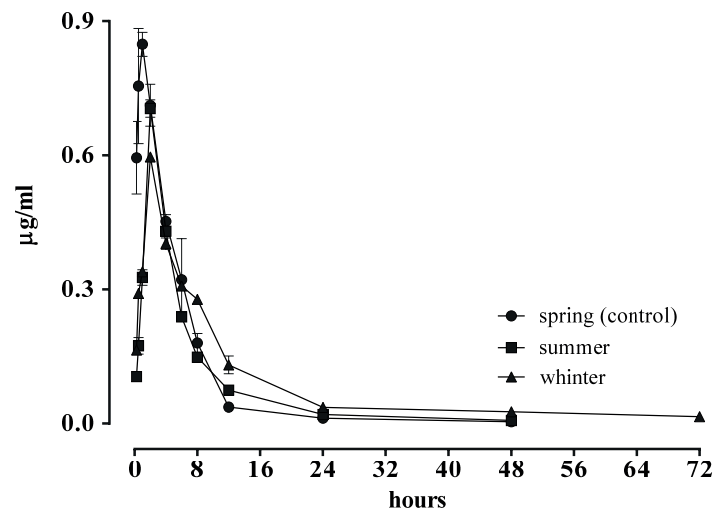

Figure 2. Plasma disposition curve concentrations of MAR $(\mu \mathrm{g} / \mathrm{ml})$ after oral administration in chickens $(2 \mathrm{mg} / \mathrm{kg})$ in different seasons

MAR concentration by oral application (Fig. 2) in winter is significantly lower $(\mathrm{p}<0.05)$ than control (spring), with a reduction in total concentration of $46 \pm 4.1 \%$. No statistically significant differences were observed with the intravenous administration between spring and the other two seasons $(\mathrm{p}>0.05)$.

In Table $1, \mathrm{C}_{\max }$ is lower $39 \pm 5.1 \%(\mathrm{p}<0.05)$ in winter than in the control period (spring). MAR has a significantly slower and lower oral absorption $(p<0.05)$ in winter and summer compared to spring, which is consistent with the $\mathrm{T}_{\max }$ of 2 hours.
Table 1 shows that the elimination of marbofloxacin depends on the season the bird has been exposed to. In winter with the oral administration (group F) there is an increase in the elimination half-life (7.6 \pm 1.4 hours), coinciding with the increase of the MRT $(9.4 \pm 0.9$ hours), determining a slower elimination and greater permanence of MAR in the chickens in winter compared to spring and summer $(\mathrm{p}<0.05)$. On the other hand, in summer by oral application of MAR (group D), it has a decreased elimination half-life ( $4.9 \pm 0.6$ hours), which coincides with the short MRT of $6.3 \pm 0.4$ hours.

In summer the total plasma clearance (7.6 \pm $0.1 \mathrm{ml} / \mathrm{min} / \mathrm{kg})$ is significantly higher $(\mathrm{p}<0.05)$ compared to the other two seasons. Oral bioavailability of MAR in $86 \pm 1.7 \%$ and $78 \pm 3.1 \%$ winter chickens was observed, decreased compared to the spring of $94 \pm 5.2 \%$.

\section{DISCUSSION}

The plasma pharmacokinetic behavior of intravenous marbofloxacin at each season of the year is similar to the one described by other authors $(4,6,7)$, with a high oral bioavailability which demonstrates that marbofloxacin maintains rapid dissolution in the intestinal environment characteristic of fluoroquinolones (17). In winter,

Table 1. MAR pharmacokinetic parameters ( $m e a n \pm s d)$ after intravenous and oral $2 \mathrm{mg} / \mathrm{kg}$ single dose in broiler chickens, at spring (A-B), summer (C-D) and winter (D-F)

\begin{tabular}{|c|c|c|c|c|c|c|}
\hline $\begin{array}{l}\text { Pharmacokinetic } \\
\text { parameters }\end{array}$ & Group A & Group C & Group E & Group B & Group D & Group F \\
\hline $\mathrm{C}_{\max }(\mu \mathrm{g} / \mathrm{ml})$ & - & - & - & $0.8 \pm 0.1$ & $0.7 \pm 0.1$ & $0.5 \pm 0.1^{*}$ \\
\hline$T_{\max }$ (hours) & - & - & - & $1.0 \pm 0.2$ & $2.0 \pm 0.0^{*}$ & $2.0 \pm 0.0^{*}$ \\
\hline$t^{1} / 2$ abs (hours) & - & - & - & $0.1 \pm 0.0$ & $0.9 \pm 0.1^{*}$ & $0.8 \pm 0.1^{*}$ \\
\hline$t^{1} / 2 \alpha$ (hours) & $0.5 \pm 0.1$ & $0.7 \pm 0.0^{*}$ & $0.5 \pm 0.0$ & $2.8 \pm 0.1$ & $1.4 \pm 0.4^{*}$ & $3.2 \pm 0.1$ \\
\hline$t^{1} / 2 \beta$ (hours) & $6.5 \pm 0.4$ & $5.3 \pm 0.4^{*}$ & $5.0 \pm 0.3^{*}$ & $4.7 \pm 0.8$ & $4.9 \pm 0.6$ & $7.6 \pm 1.4^{*}$ \\
\hline $\operatorname{AUC}(\mu \mathrm{g}-\mathrm{h} / \mathrm{ml})$ & $5.0 \pm 0.55$ & $4.3 \pm 0.1^{*}$ & $5.2 \pm 0.15$ & $4.7 \pm 0.3$ & $3.7 \pm 0.17^{*}$ & $4.1 \pm 0.1^{*}$ \\
\hline F (\%) & - & - & - & $94.0 \pm 5.2$ & $86.0 \pm 1.7$ & $78.0 \pm 3.1$ \\
\hline Vdarea(L/kg) & $3.7 \pm 0.3$ & $3.5 \pm 0.1$ & $2.7 \pm 0.2^{*}$ & $2.8 \pm 0.5$ & $3.3 \pm 0.5$ & $4.3 \pm 0.7^{*}$ \\
\hline MRT (hours) & $6.6 \pm 0.2$ & $4.3 \pm 0.0^{*}$ & $4.9 \pm 0.3^{*}$ & $4.9 \pm 0.1$ & $6.3 \pm 0.4^{*}$ & $9.4 \pm 0.9^{*}$ \\
\hline $\operatorname{Clt}(\mathrm{ml} / \mathrm{min} / \mathrm{kg})$ & $6.6 \pm 0.4$ & $7.6 \pm 0.1^{*}$ & $6.3 \pm 0.1$ & $6.5 \pm 0.3$ & $7.5 \pm 0.0^{*}$ & $6.3 \pm 0.2$ \\
\hline
\end{tabular}

Abbreviations: $\mathrm{C}_{\max }$, maximum plasma concentration; $\mathrm{T}_{\max }$, time to peak concentration; $\mathrm{t} 1 / 2 \mathrm{abs}$, absorption half-life; $\mathrm{t}^{1} / 2 \alpha$ distribution half-life; $t^{1 / 2} \beta$ elimination half-life; AUC, area under the curve; F (\%), bioavailability; Vd area, volume of distribution; MRT, mean residence time and $\mathrm{Clt}$, total plasma clearance. $(*)$ Statistically significant differences $(\mathrm{p}<0.05)$ between the control group $(\mathrm{A}-\mathrm{B})$ and the study periods (C, D, E, F) 
the detection of MAR in plasma is extended to 72 hours post application.

The rapid oral absorption, wide distribution and moderate elimination of MAR observed in birds in the spring is similar to that obtained by other authors $(4,6,7)$. The oral absorption of MAR in summer and winter is slower and smaller compared to spring. A decrease of $15 \pm 0.8 \%$ and $39 \pm 5.1 \%$ of Cmax was observed in both summer and winter, coinciding with the decrease in oral bioavailability. This is due to the low hardiness of chickens to ambient temperature variations, with an ideal range between 18 to $22{ }^{\circ} \mathrm{C}$ (18). This leads to rapid thermoregulatory physiological responses, such as slowing and diminution of the intestinal and stomach peristaltic movements, without modifying those of the proventriculus $(19,20)$.

There is evidence that fattening chickens exposed to temperatures of $31^{\circ} \mathrm{C}$ present alteration in the enterocytes and intestinal mucosa, reducing the absorption capacity (21), which may be due to the decrease in bioavailability of marbofloxacin in summer.

The pharmacokinetic parameters of marbofloxacin: clearance, elimination half-life $\left(\mathrm{t}_{2 / 1} \beta\right)$ and MRT (Table 1) by intravenous and oral application, determine that the elimination of MAR in broiler chickens is faster in summer due to the physiological changes that the organism exerts to non-evaporative heat loss, by increasing water consumption and urine production (19).

The physiological mechanism of thermoregulation in birds is regulated on the one hand by the vasomotor system. In cold situations, peripheral vasoconstriction is present to irrigate the most important organs (brain, liver, lungs, etc.), explaining the greater persistence of MAR in winter (72 hours), whereas in heat situations peripheral vasodilation and increased blood flow velocity are developed, eliminating non-evaporative heat $(19,22)$, coinciding with the rapid elimination of MAR in summer (48 hours).

The rapid elimination of antibiotics in summer was not observed by Nawaz (23) in sheep for sulphadimidine, rather a slower elimination in summer, assigning this difference to the physiological difference in the thermoregulation of birds and mammals.

Finally, Sun et al. (24) in Paralichthysolivaceus worked with different water temperatures and the pharmacokinetic behavior of difloxacin, concluding like our study that in summer there is a significantly higher rate of drug clearance and decreased half-life elimination, which coincides with the pharmacokinetic results of our study.

\section{CONCLUSION}

The conclusion is that in summer and winter there is a decrease in the plasma concentrations of marbofloxacin by oral application in broiler chickens compared to spring, significantly modifying the pharmacokinetic parameters.

It was determined that the therapeutic use of marbofloxacin in broiler chickens varies according to the season of the year, probably due to the physiological thermoregulatory responses of the bird to the ambient temperatures. It is of importance in later studies to see if it modifies the pharmacological residues that can have repercussions in humans as animal producing food. This last point will be investigated in future studies.

\section{CONFLICT OF INTEREST STATEMENT}

The authors declared that they have no potential conflict of interest with respect to the authorship and/or publication of this article

\section{ACKNOWLEDGEMENT}

Part of this work was supported by the Secretary of Science and Technology of the National University of Rio Cuarto (PPI Project 2016-2018).

\section{REFERENCES}

1. Anadón, A., Martínez-Larraga-a, M., Fernández-Cruz,M. (1993). Physiological and pharmacological considerations in aviary therapy. Rev. Med. Vet. 144 (10): 745-757.

2. Landoni, M., Albarellos, G. (2015). The use of antimicrobial agents in broiler chickens. Vet. J. 205, 21-27.

https://doi.org/10.1016/j.tvj1.2015.04.016 PMid:25981931

3. Hofacre, C. (2007). Antimicrobial drug use in poultry. In: B.D. Gigueré S. Prescott (Eds.), An antimicrobial therapy in veterinary medicine (pp. 545-553). Iowa: Blackwell Pub.

4. Ding, H., Wang, L., Shen, X., Gu, X., Zeng, D., Zeng, Z. (2013). Plasma and tissue pharmacokinetics of marbofloxacin in experimentally infected chickens with Mycoplasma gallisepticum and Escherichia coli. J. Vet. Pharmacol. Ther. 36, 511-515. https://doi.org/10.1111/jvp.12049 PMid:23550715 
5. El-Komy, A., Attia, T., El Latif, A., Fathy, H. (2016). Bioavailability pharmacokinetics and residues of marbofloxacin in normal and E. coli infected broiler chicken. In. J. Pharmacol. Tox. 2 (4): 144-149.

6. Huang, X., Chen, Z., Zhang, S., Zeng, Z. (2003). Influence of experimentally Pasteurella multocida infection on the pharmacokinetics of marbofloxacin in broiler chickens. Acta Veterinaria et Zootechnica Sinica 34, 98-102.

7. Anadón, A., Martínez-Larraga-a, M., Días, M., Martínez, M., Frejo, M., Martínez, M., Tafur, M., Castellano., V. (2002). Pharmacokinetic characteristics and tissue residues for marbofloxacin and its metabolite N-desmethyl-marbofloxacin in broiler chickens. AJVR. 63, 927-933. https://doi.org/10.2460/ajvr.2002.63.927

8. Yuan, L., Wang, R., Sun, L., Zhu, L., Luo, X., Sun, J., Fang, B., Liu, Y. (2010). Pharmacokinetics of marbofloxacin in Muscovy duck (Cairina moschata). J. Vet. Pharmacol. Ther. 34, 82-85. https://doi.org/10.1111/j.1365-2885.2010.01207.x PMid:21219349

9. Martinez, M., Modric, S. (2009). Patient variation in veterinary medicine: Part I. Influence of altered physiological states. J. Vet. Pharmacol. Ther. 33, 213-226.

https://doi.org/10.1111/j.1365-2885.2009.01139.x PMid:20557438

10. Martinez, M., Modric, S. (2010). Patient variation in veterinary medicine: Part II. Influence of physiological variables. J. Vet. Pharmacol. Ther. 34, 209-223. PMid:21083665

11. Toutain, P., Ferran, A., Bousquet-Mélou, A. (2010). Species differences in pharmacokinetics and pharmacodynamics. In: F. Cunningham, J. Elliott, P. Lees (Eds.), Comparative and veterinary pharmacology (pp. 19-48). Francia: Springer Berlin Heidelberg. https://doi.org/10.1007/978-3-642-10324-7_2

12. Böttcher, S., Baum, H., Hoppe-Tychy, T., Benz, C. (2001). An HPLC assay and a microbiological assay to determine levofloxacin in soft tissue, bone, bile and serum. J. Pharm. Biomed. Anal. 25, 197-203. https://doi.org/10.1016/S0731-7085(00)00478-7

13. Urzúa, N., Errecalde, C., Prieto, G., Lüders, C., Picco, E., Paula Tonini, M. (2016). Plasma pharmacokinetics and muscle disposition of marbofloxacin in chickens. IJVM. 1, 1-6.

14. Farrier, D.S. (1999). PK Solutions 2.0, Noncompartmental pharmacokinetics. Data analysis. Ashland, USA.
15. Toutain, P., Bousquet-Mélou, A. (2004). Bioavailability and its assessment. J. Vet. Pharmacol. Ther. 7, 455-466.

https://doi.org/10.1111/j.1365-2885.2004.00604.x PMid:15601440

16. Di Rienzo, J., Casanove F., Balzarini M., Gonzales, L., Tablada, M., Robledo, C. (2016). InfoStat versión 2016. Group InfoStat. FCA. Universidad Nacional de Cordoba. Argentina. www.infostat.com.ar

17. Scholar, E. (2002). Fluoroquinolones: past, present and future of a novel group of antibacterial agents. Am. J. Pharm Educ. 66, 164-172.

18. Estrada, P., Márquez, G. (2005). Interactions of environmental factors with productive behavior response in broiler chickens. Colombian Journal of Animal Sciences 18, 256-273.

19. Whittow, G. (1976). Regulation of body temperature. In: P.D Sturkie (Ed.), Avian Physiology (pp. 152-189). New York Inc: Springer-Verlag. https://doi.org/10.1007/978-3-642-96274-5_7

20. Hai, L., Rong, D., Zhang, Z. (2000). The effect of thermal environment on the digestion of broilers. J. Anim. Physio. Anim. Nutr. 83, 57-64. https://doi.org/10.1046/j.1439-0396.2000.00223.x

21. Quinteiro-Filho, W., Rodrigues, A., Ribeiro, V., Ferraz-de-paula, M., Pinheiro, L., Palermo-neto, J. (2010). Acute heat stress impairs performance parameter sand induces mild intestinal enteritis in broiler chickens: Role of acute HPA axis activation. J. Anim. Sci. 90, 1986-1994.

https://doi.org/10.2527/jas.2011-3949 PMid:22228037

22. Yahav, S. (2015). Regulation of body temperature: strategies and mechanisms. In: G. Colin (Ed.), Sturkie's Avian Physiology (pp. 869-897). London: Elsevier.

https://doi.org/10.1016/B978-0-12-407160-5.00037-3

23. Nawaz, M., Nawaz, R. (1983). Pharmacokinetics and urinary excretion of sulphadimidine in sheep during summer and winter. Vet Rec. 16, 379-381. https://doi.org/10.1136/vr.112.16.379

24. Sun, M., Li, J., Gai, C., Chang, Z., Li, J., Zhao, F. (2014). Pharmacokinetics of difloxacin in olive flounder Paralichthysolivaceus at two water temperatures. J. Vet. Pharmacol. Ther. 37, 186-191. https://doi.org/10.1111/jvp.12062 PMid:23742101 